\title{
JAUNŲ IR VYRESNIOJO AMŽIAUS ŽMONIŲ PUSIAUSVYROS KONTROLÉS YPATUMAI
}

\author{
Laimutis Škikas, Kazimieras Muckus \\ Lietuvos kūno kultūros akademija, Kaunas, Lietuva
}

Laimitis Škikas. Lietuvos kūno kultūros akademijos biomedicinos mokslų krypties doktorantas. Mokslinių tyrimų kryptis — čiurnos ir kelio
sąnario sportinės traumos, jų poveikis blauzdos dvilypio raumens fiziologiniams, biomechaniniams ypatumams ir pusiausvyrai.

\section{SANTRAUKA}

Vienas iš veiksniu, lemiančiu vyresniojo amžiaus žmoniu funkcinę nepriklausomybę ir gyvenimo kokybę, yra pusiausvyros stabilumas. Šio tyrimo tikslas - ištirti, ar brandaus darbingo amžiaus žmoniu (30-45 m.) pusiausvyros kontrolès sistema veikia taip pat gerai, kaip ir jaunu (20-25 m.)? Buvo tiriama septyniolika 20-24 metu jaunu (9 merginos ir 8 vaikinai) ir dešimt 30-45 metu žmoniu (6 vyrai ir 4 moterys), sistemingai kultivuojančiu küno kultüra.

Tyrimo metu taikème statinès stabilografijos metoda. Tiriamieji nuleidę rankas ir suglaudę kojas turèjo ramiai stovèti viena minute ant jègos plokštès. Stabilograma (slègio centro koordinačiu kitimo kreives strèlinèje ir skersinèje ašyje) registravome jègos plokšte, kompiuterine iranga analizavome signalus. Registruojamo signalo diskretizacija $10 \mathrm{~ms}$. Stabilogramos registravimo trukmè $60 \mathrm{~s}$. Vertinome slègio centro (SC) poslinki skersinèje ir strèlinèje ašyje, SC svyravimo vidutini greiti. Atlikdami SC dažnine analize taikème vilneliu metoda. Vyresniojo amžiaus žmoniu SC svyravimu amplitudè skersineje ir strèlinèje ašyje, vidutinis svyravimo greitis buvo reikšmingai didesni $(p<0,01)$ nei jaunu žmoniu. Ir jaunu, ir vyresniu žmoniu SC svyravimu amplitudè skersineje ašyje, vidutinis svyravimo greitis reikšmingai padidèja tiriamajam užsimerkus, tačiau mažai keičiasi svyravimu amplitudè strèlinèje ašyje. Vyresniu žmoniu SC svyravimai skersinejje ašyje reikšmingai didesni aukštesniu dažniu srityje (0,312-1,25 Hz). Sis skirtumas labiau išreikštas užmerkus akis. Vyresniu atsimerkusiu žmoniu reikšmingai didesni lèti $(0,078 \div 0,156 \mathrm{~Hz}) \mathrm{SC}$ svyravimai strèlinèje ašyje. Užsimerkusio tiriamojo SC svyravimai reikšmingai didesni visame dažniu diapazone.

Išvados: a) 30-45 m. amžiaus žmoniu pusiausvyros kontrole yra mažiau veiksminga, lyginant su jaunais (20-24 m.); b) ir jaunu, ir vyresniu žmoniu SC svyravimu amplitudè skersinejje ašyje ir vidutinis svyravimo greitis reikšmingai padideja užmerkus akis, tačiau mažai keičiasi svyravimu amplitudè strèlinèje ašyje. Tai rodo, kad rega svarbesnè SC svyravimams skersineje, bet ne strèlinèje ašyje.

Raktažodžiai: stabilografija, pusiausvyros kontrolè, vilneliu transformacija.

\begin{abstract}
IVADAS

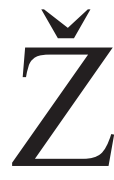
mogaus pusiausvyra ir jos išlaikymas itin sudètingas procesas, kuriam apibūdinti vartojama be galo daug apibrèžimų. Kadangi žmogaus pusiausvyros pastovumas yra reliatyvus, iš esmès gali būti apibrèžiama tik pusiausvyros kontrolè. Vienu atveju teigiama, kad pusiausvyra yra fizinė ypatybè, gebėjimas išlaikyti santykiškai pastovią kūno padèti įvairiomis pozomis, atliekant skirtingus judesius ar veiksmus, veikiant išorès jè-
\end{abstract}

goms (Sporto terminu žodynas, 1996), kitu — kad nuolatinis kūno padèties kitimas, norint nenukristi, nenugriūti (Duarte, Zatsiorsky, 2002), trečiu gebejjimas reguliuoti kūno sunkio jègos linijos padètį atramos ploto atžvilgiu (Pollock et al., 2000). Tačiau visuomet pabrèžiama, kad pusiausvyra priklauso nuo gebejjimo integruoti gausią sensorinę informaciją ir reguliuoti daugiasegmentès biomechaninès sistemos padèti. 
Nekintamos padèties išlaikymas priklauso nuo trijų svarbiausių komponentų sąveikos (Nashner, 2001):

1. Informacijos apie kūno ir kūno segmentų orientaciją iš regos analizatoriaus, vidinès ausies vestibulinio aparato ir propriorecepciniu jutimu, kylančių dẻl kontakto su atrama, dermès.

2. Motorinių reakcijų, koordinuojančių pėdų, kojų ir liemens raumenu veikla.

3. CNS funkcinių galimybiu integruoti minètus sensorinius ir motorinius procesus bei gebejjimo juos modifikuoti ir pritaikyti kintančioms aplinkos sąlygoms.

Didejjant senstančių gyventojų skaičiui ir ilgejjant gyvenimo trukmei, vis svarbiau palaikyti kūno judruma, taigi ir funkcinę nepriklausomybę. Vienas iš veiksnių, lemiančių vyresniojo amžiaus žmoniu funkcinę nepriklausomybe ir gyvenimo kokybę, yra pusiausvyros stabilumas (Spirduso, 1995; Jančova, 2008). Palaikyti ir stabilizuoti pusiausvyrą su amžiumi darosi vis sunkiau (Winter et al., 1996; Megrot et al., 2002). Kai susilpnejja regimujų, vestibuliniu ir somatosensoriniu sistemu sąveika, mažiau stabili darosi stovèsena, be abejo, padideja ir griuvimo rizika (MacKinnon, Winter, 1993; Horak, Diener, 1994). Pagyvenusių žmonių pusiausvyros kontrolès sistemos degeneracija (Wolley et al., 1996) ir svarbiausios patologijos priverte tyrejus ir klinicistus labiau domètis, kaip dirba sistema ir kaip įvertinti jos būsena. Daugelis tyrimu parodè, kad pusiausvyros stabilumo rodikliai gerai koreliuoja su griuvimų rizika (Jančova, 2008).

Nors vyresniojo ir senyvo amžiaus žmoniu pusiausvyros tyrimų atlikta nemažai (Pyykko et al., 1990; Nakamura et al., 2001; Demura et al., 2005; Termoza et al., 200;), dauguma jų skirti vyresnių kaip 65 metu asmenų pusiausvyrai tirti. Be to, niekas iš autorių netyrinèjo slègio centro (SC) svyravimų dažnio dedamujų. Nors nemažai atlikta SC svyravimų dažnio tyrimų (Williams et al., 1997; Giacomini et al., 1998), dauguma ju paremti paprasta Furje signalu analize. Ankstesni mūsų (Muckus et al., 2009) ir kitų autoriu tyrimai (Williams et al., 1997; Giacomini et al., 1998) rodo, kad SC svyravimu dažnio analize svarbi atskleidžiant regos, vestibulinio aparato ir propriorecepcijos reikšmę pusiausvyros kontrolei.
Mūsų tyrimo tikslas - ištirti, ar brandaus darbingo amžiaus žmoniu ( $30-45 \mathrm{~m}$.) pusiausvyros kontrolès sistema veikia taip pat gerai kaip ir jaunu $(20-25 \mathrm{~m}$.$) ?$

\section{TYRIMO METODIKA}

Buvo tiriama septyniolika $20-24$ metu jaunu ( 9 merginos ir 8 vaikinai) ir dešimt 30-45 metu žmoniu (6 vyrai ir 4 moterys), sistemingai kultivuojančių kūno kultūrą.

Tyrimo metu taikème statinès stabilografijos metodą. Tiriamieji nuleidę rankas ir suglaudę kojas turèjo ramiai stovèti vieną minutę ant jègos plokštès. Stabilogramą (slègio centro koordinačiu kitimo kreives strèlinèje ir skersinejje ašyje) registravome tiriamiesiems stovint atmerktomis ir užmerktomis akimis. Stabilogramą analizavome mūsų pačių sukurta signalų analizès programine iranga (Muckus et al., 2009). Registruojamo signalo diskretizacija $10 \mathrm{~ms}$. Stabilogramos registravimo trukmè $60 \mathrm{~s}$. Vertinome slègio centro (SC) poslinkị skersinèje $(\Delta x)$ ir strèlinèje $(\Delta y)$ ašyje, SC svyravimo vidutini greiti $(\bar{v})$.

SC padèti rodantis signalas yra stochastinis, tačiau žinomi atskirų bendrosios sistemos sandų veiklos signalo dedamuju dažnio ypatumai. Todèl šio signalo laiko-dažnio rodikliai atskleidžia atskirų sistemos dalių veikimą. Diskretinè vilneliu transformacija, pasitelkiant Daubechie šeimos 4 eilès vilneles (Mallat, 1999), naudota SC padeties signalo dekompozicijai nustatyti. Išskirti 6 skirtingų dažnių spektro juostų signalo sandai (1 lent.).

SC padeties signalas, kaip ir jo sandai, anot B. P. Mulgrew ir kt. (1998), yra galios signalas (jo integralas intervalu nuo $-\infty$ iki $\infty$ yra begalinis). Todèl kiekvieno sando galia buvo lygi:

$$
P_{S}=\frac{1}{N} \sum_{i=0}^{N-1}\left|s_{i}-M_{S}\right|^{2},
$$

čia $\mathrm{s}_{\mathrm{i}}$ - eilinis $\mathrm{S}$ sando atskaitymas, $\mathrm{M}_{\mathrm{S}}$ - šio sando vidurkis.

Analizuodami duomenis naudojome programini paketą MS Office EXCEL 2003. Nulinè hipotezè apie vidurkiu lygybę skirtingomis sąlygomis pagal dviejų veiksnių dispersinę analizę atmetama, kai $p$ reikšmè maženè už nuli $(\mathrm{p}<0,05)$.

\begin{tabular}{|l|c|c|c|c|c|c|}
\hline Sando Nr. & $\mathbf{1}$ & $\mathbf{2}$ & $\mathbf{3}$ & $\mathbf{4}$ & $\mathbf{5}$ & $\begin{array}{l}1 \text { lentelè. SC padėties signalo } \\
\text { dažnio charakteristikų san- } \\
\text { dai }\end{array}$ \\
\hline Dažnis, $\mathrm{Hz}$ & $2,5 \div 5,0$ & $1,25 \div 2,5$ & $0,625 \div 1,25$ & $0,312 \div 0,625$ & $0,156 \div 0,312$ & $0,078 \div 0,156$ \\
\hline
\end{tabular}


2 lentelè. Stabilometriniai rodikliai tiriamiesiems stovint atsimerkus ir užsimerkus

Pastaba. Pateikta: vidurkis \pm standartinè paklaida. * - rodiklis reikšmingai skiriasi $(\mathrm{p}<0,01)$, lyginant su rodikliais atmerktomis akimis.

1 pav. SC svyravimų rodikliai tiriamiesiems stovint atsimerkus (A) ir užsimerkus (B)

\begin{tabular}{|l|c|c|c|c|}
\hline \multirow{2}{*}{ Rodikiamieji } & \multicolumn{2}{|c|}{ Jauni } & \multicolumn{2}{c|}{ Vyresni } \\
\cline { 2 - 5 } & Atsimerkus & Užsimerkus & Atsimerkus & Užsimerkus \\
\hline$\Delta x, \mathrm{~mm}$ & $22,3 \pm 1,94$ & $27,2 \pm 2,13^{*}$ & $31,8 \pm 2,86$ & $43,2 \pm 5,27^{*}$ \\
\hline$\Delta y, \mathrm{~mm}$ & $23,2 \pm 1,85$ & $25,1 \pm 1,75$ & $40,9 \pm 4,15$ & $45,5 \pm 4,23$ \\
\hline $\bar{v}, \mathrm{~mm} / \mathrm{s}$ & $11,9 \pm 0,73$ & $18,0 \pm 1,15^{*}$ & $15,9 \pm 1,14$ & $28,2 \pm 2,05^{*}$ \\
\hline
\end{tabular}

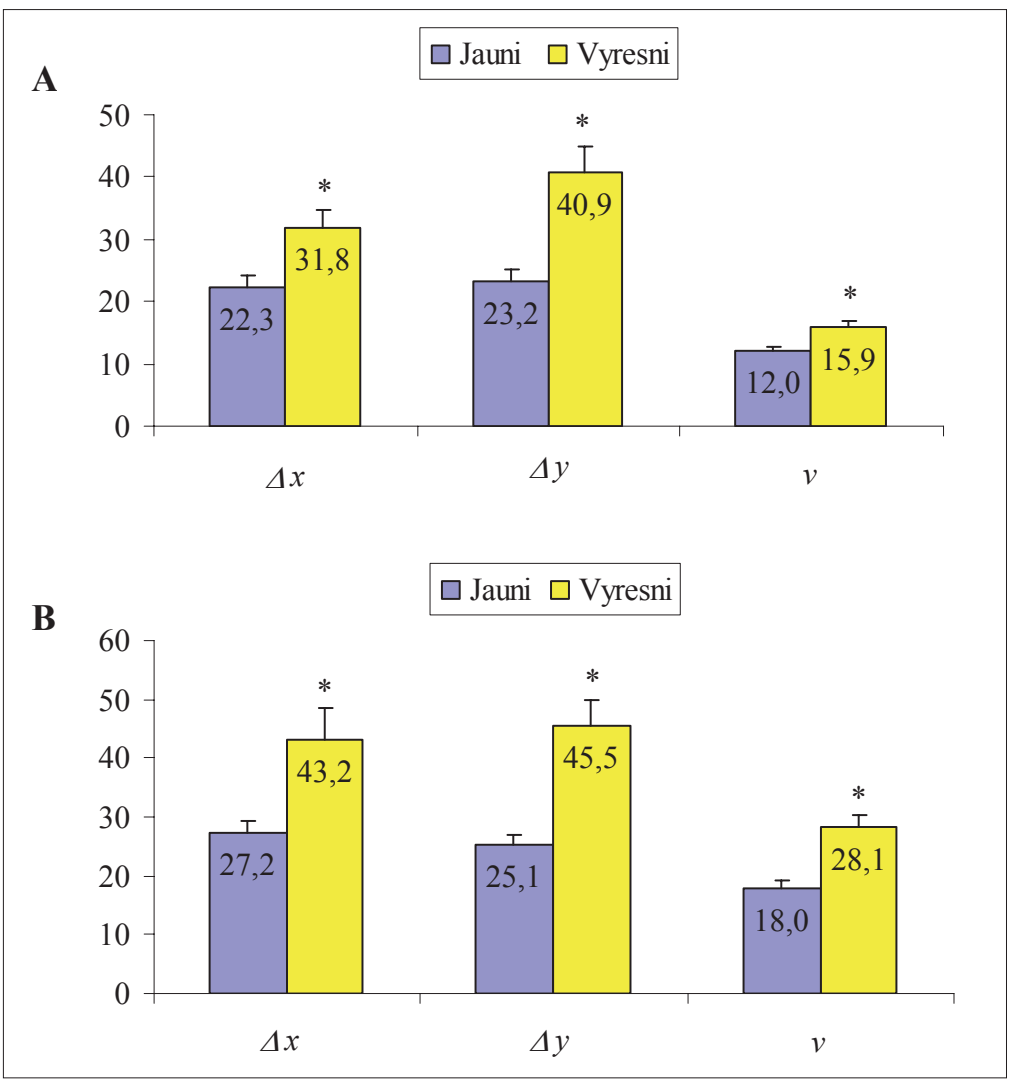

Pastaba. $\Delta x-\mathrm{SC}$ poslinkis skersineje ašyje $(\mathrm{mm}) ; \Delta y-$ strèlinèje ašyje; $\bar{v}-\mathrm{SC}$ svyravimo vidutinis greitis $(\mathrm{mm} / \mathrm{s})$. Parodyta vidurkis \pm standartinè paklaida. ${ }^{*}-\mathrm{p}<0,01$, lyginant jaunų ir vyresnių tiriamujų $\mathrm{SC}$ svyravimų rodiklius.

\section{REZULTATAI}

1 paveiksle pateikti jaunu ir vyresniojo amžiaus žmonių SC svyravimų rodikliai tiriamiesiems atmerkus (A) ir užmerkus (B) akis. Vyresniojo amžiaus žmonių SC svyravimų amplitude skersinèje ir strèlinėje ašyje, vidutinis svyravimo greitis reikšmingai didesni $(\mathrm{p}<0,01)$ nei jaunų. Kaip jaunų, taip ir vyresnių žmonių SC svyravimu amplitudė skersinèje ašyje ir vidutinis svyravimo greitis reikšmingai padideja tiriamajam užmerkus akis, tačiau mažai keičiasi svyravimų amplitudè strèlinèje ašyje (2 lent.).

2 paveiksle parodyta jaunų ir vyresnių žmonių SC svyravimo skersinejje ašyje sandų galios kitimas tiriamiesiems stovint atmerktomis (A) ir užmerktomis (B) akimis. Vyresnių žmonių SC svyravimai reikšmingai didesni aukštesnių dažnių srityje $(0,312-1,25 \mathrm{~Hz})$. Šis skirtumas labiau išreikštas tiriamiesiems užsimerkus. Tuo tarpu strèlinèje ašyje atsimerkusių vyresnių žmonių reikšmingai didesni lèti $(0,078 \div 0,156 \mathrm{~Hz}) \mathrm{SC}$ svyravimai (3A pav.). Tiriamiesiems užmerkus akis, SC svyravimai reikšmingai didesni visame dažnių diapazone (3B pav.).

\section{REZULTATŲ APTARIMAS}

Atlikto tyrimo rezultatai rodo, kad vyresniu žmonių SC svyravimai didesni nei jaunų atsimerkus ir užsimerkus. Ir jaunų, ir vyresnių žmonių SC svyravimų amplitude skersineje ašyje, vidutinis svyravimo greitis reikšmingai padidèja užmerkus akis, tačiau svyravimų amplitudè mažai keičiasi strèlinèje ašyje (2 lent.). Vadinasi, rega svarbesnè SC svyravimams skersinëje, bet ne strèlinėje ašyje.

Dauguma vyresniojo ir senyvo amžiaus žmonių pusiausvyros tyrimų atlikti tarp vyresnių kaip 

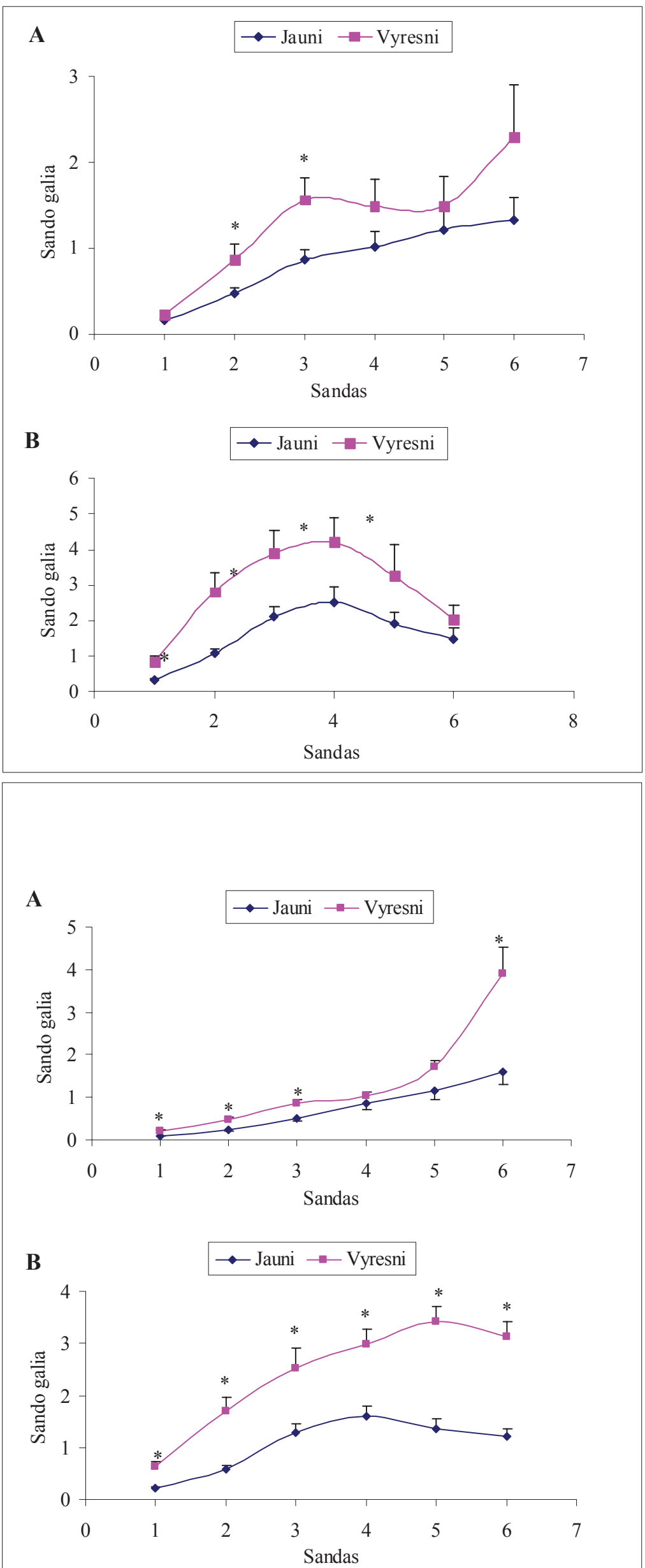

2 pav. SC svyravimo skersinėje ašyje sando galios kitimas tiriamiesiems stovint atsimerkus (A) ir užsimerkus (B).

Pastaba. Parodyta: vidurkis \pm standartine paklaida. * - p $<0,01$, lyginant jaunų ir vyresnių tiriamuju SC svyravimo rodiklius.

3 pav. SC svyravimo strèlinėje ašyje sando galios kitimas tiriamiesiems stovint atsimerkus (A) ir užsimerkus (B).

Pastaba. Parodyta: vidurkis \pm standartine paklaida. * $-\mathrm{p}<0,01$, lyginant jaunų ir vyresnių tiriamujų SC svyravimo rodiklius. 
65 metų amžiaus žmonių (Pyykko et al., 1990; Nakamura et al., 2001; Demura et al., 2005; Termoza et al., 2008). Mūsų tyrimai rodo, kad jau $30-45$ metu amžiaus žmonès blogiau kontroliuoja pusiausvyrą nei jauni.

Vyresniojo amžiaus žmonių pusiausvyros stabilumas tiesiogiai susijęs su regejjimo aštrumu. 65 metu ir vyresnių asmenu, turinčių regèjimo sutrikimu, funkcinè pusiausvyra buvo tiriama naudojant Berg pusiausvyros skalę. Tyrimų rezultatai parodè, kad pusiausvyros rodikliai blogèja mažèjant regèjimo aštrumui (Lee, Scudds, 2003).

H. C. Diener ir kt. (1982) analizavo pusiausvyros palaikymą posturografijos bei elektromiografijos metodu ir pastebejo, kad žmogui užsimerkus pusiausvyra stabilizuojama kojų raumenimis, tačiau veiksmingiausia pusiausvyros stabilizacija yra dalyvaujant regai - tada geriausiai suderinami tarpsegmentiniai galvos, liemens ir koju judesiai.

Y. Katayama ir kt. (2004) ištyrè, kad regimosios informacijos neturejimas stovint suglaustomis kojomis lemia 1,5 karto didesnę svyravimų amplitudę, o stovint ant vienos kojos - net 3 kartus didesnius svyravimus.

Tam tikrą informaciją apie pusiausvyros kontrolès mechanizmus suteikia SC svyravimų dažnio analizè. Nors nemaža tyrimų atlikta analizuojant SC svyravimų dažni (Williams et al., 1997; Giacomini et al., 199;), dauguma ju paremti paprasta Furje signalų analize. Ankstesni mūsų (Muckus et al., 2009) ir kitu autoriu tyrimai (Williams et al., 1997; Giacomini et al., 1998) rodo, kad SC svyravimų dažnio analizè yra svarbi atskleidžiant regos, vestibulinio aparato ir propriorecepcijos indèli pusiausvyros kontrolei.

Nors nèra aiškiai įrodyta, kokio dažnio SC svyravimus lemia regimoji, vestibulinè ir somatosensoriné informacija, manoma, kad vestibulinis aparatas lemia lètus $(<0,7 \mathrm{~Hz})$, rega — vidutinio dažnio $(0,7-1,0 \mathrm{~Hz})$, somatosensorinè sistema aukštesnio dažnio $(>1,0 \mathrm{~Hz})$ svyravimus (Giacomini et al., 1998).

Normalu senéjimo prosesą paprastai lydi Ł̇vairūs nervų ir raumenų sistemos pokyčiai. Su amžiumi silpnejja raumenys, sumažèja odos jautrumas, nusilpsta propriorecepcija, sumažèja nervinio impulso sklidimo greitis (Collins et al., 1995). Tai tikriausiai ir yra vyresniojo amžiaus žmonių pusiausvyros kontrolès sutrikimų priežastys.

\section{IŠVADOS}

30-45 m. amžiaus žmonių pusiausvyra kontroliuojama prasčiau, lyginant su jaunais žmonèmis $(20-24 \mathrm{~m}$.).

Ir jaunų, ir vyresnių žmonių SC svyravimų amplitudè skersinèje ašyje, vidutinis svyravimo greitis reikšmingai padidèja jiems užmerkus akis, tačiau mažai keičiasi svyravimu amplitudè strèlinèje ašyje. Tai rodo, kad rega svarbesnè SC svyravimams skersinejje, bet ne strèlinèje ašyje.

\section{LITERATŪRA}

Collins, J. J., De Luca, C. J., Burrows, A., Lipsitz, L. A. (1995). Age-related changes in open-loop and closedloop postural control mechanisms. Experimental Brain Research, 104 (3), 480-92.

Demura, Sh., Kitabayashi, T., Kimura, A., Matsuzawa, J. (2005). Body sway characteristics during static upright posture in healthy and disordered elderly. Journal of Physiological Anthropology and Applied Human Science, 24 (5), 551-555.

Diener, H. C., Dichgans, J., Bruzek, W., Selinka, H. (1982). Stabilization of human posture during induced oscillations of the body. Experimantal Brain Research, 45 (1), 126-132.

Duarte, M., Zatsiorsky, V. M. (2002). Effects of body lean and visual. information on the equilibrium maintenance during stance. Experimental Brain Research, 146, $60-69$.

Giacomini, P., Sorace, F., Margini, A. (1998). Alterations in postural. control: The use of spectral analysis in stability measurement. Acta Otorhinolaryngol, 18 (2), 83-87.

Horak, F. B., Diener, H. C. (1994). Cerebellar control in postural scaling and central set in stance. Journal of Neurophysiology, 2, 479-490.
Jančova, J. (2008). Measuring the bal.ance control system - review. Acta medica (Hradec Kralové), 51 (3), 129-137. Prieiga internetu: http://www.lfhk.cuni.cz/Data/ files/Casopisy/2008/2008_129.pdf

Katayama, Y., Senda, M., Hamada, M. et al. (2004). Relationship between postural balance and knee and toe muscle power inyoung woman. Acta Medica Okayama, 58 (4), 189-195.

Lee, H. K., Scudds, R. J. (2003). Comparison of balance in older people with and without visual impairment. Age and Ageing, 32 (6), 643-649.

MacKinnon, C. D., Winter, D. A. (1993). Control of whole body bal.ance and posture in the frontal. plane during wal. king. Journal of Biomechanics, 26, 633-644.

Mallat, S. G. (1999). A Wavelet Tour of Signal Processing. Academic Press.

Megrot, F., Bardy, B. G., Dietrich, G. (2002). Dimensionality and the dynamics of human unstable equilibrium. Journal of Motor Behavior, 34, 323-328.

Muckus, K., Juodžbalienė,V., Kriščiukaitis, A., Pukènas, K., Škikas, L. (2009). The gastrocnemius muscle stiffness and human balance stability. Mechanika, 6 (80), 18-22. 
Mulgrew, B. P., Grant, Thompson, J. et al. (1998). Digital Signal Processing Concepts \& Applications. Basingstoke, UK: Palgrave Macmillan.

Nakamura, H., Tsuchida, T., Mano, Y. (2001). The assessment of posture control in the elderly using the displacement of the center of pressure after forward platform translation. Journal of Electromyography and Kinesiology, 11 (6), 395-403.

Nashner, L. M. (2001). Computerized dynamic posturography. Practical Management of the Dizzy Patient. $143-170$.

Pyykko, I., Jantti, P., Aalto, H. (1990). Postural control in elderly subjects. Age and Ageing, 19 (3), 215-221.

Pollock, A. S., Durward, B. R., Rowe, P. J. (2000). What is balance? Clinical Rehabilitation, 14, 402-406.

Spirduso, W. W. (1995). Physical Dimensions of Aging. Human Kinetics Publisher.
Sporto terminu žodynas. (1996). Sud. S. Stonkus. T 1. P. 675.

Termoza, N., Hal.lidayb, S. E., Winterc, D. A. et al. (2008). The control of upright stance in young, elderly and persons with Parkinson's disease. Gait \& Posture, 27 (3), $463-470$.

Williams, H. G., McClenaghan, B. A., Dickerson, J. (1997). Spectral characteristics of postural. control in elderly individuals. Archives of Physical Medicine and Rehabilitation, 78, 737-744.

Winter, D. A., Prince, F., Frank, J. S., Powel, C., Zabjek, K. F. (1996). Unified theory regarding the $a / p$ and $\mathrm{m} / \mathrm{l}$ bal.ance in quiet stance. Journal of Neurophysiology, 75, 2334-2343.

Wolley, S., McCarter, J., Randolf, B. (1996). An assesment of foam support surfaces used in static stabilometry. Gait and Posture, 4, 110.

\title{
POSTURAL CONTROL PECULIARITIES OF YOUNG AND OLDER PEOPLE
}

\author{
Laimutis Škikas, Kazimieras Muckus \\ Lithuanian Academy of Physical Education, Kaunas, Lithuania
}

\begin{abstract}
With the increase in aging population and with increased life expectancy of the elderly, the importance of maintaining mobility, and consequently functional independence, is becomming more and more important. One of factors which determines functional independence is postural stability in the sense of maintaining the upright posture. The aim of this sudy was to determine the age, when the disorders of postural control expose. Is the postural control of mature, able-bodied population (30-45 years) as good as that of the young ( $20-25$ years) people? The study included 17 young persons ( 9 girls and 8 boys, age 20 to 24 years) and 10 older persons ( 6 men and 4 women, $30-45$ years old), engaged in systematic physical training. The force plate and software for analysis of the signals was used for static posturography. The sampling rate of the signal was $10 \mathrm{~ms}$. The duration of the stabilogram recording was $60 \mathrm{~s}$. The center of pressure (COP) dislocation amplitude in transverse and sagittal direction, the mean velocity of COP sways were estimated. Multiresolution analysis based on discrete wavelet transform using 4th order Daubechie family wavelets was used for COP signal decomposition. In older people population, COP dislocation in transverse and sagital directions, and the the mean velocity of COP sways were significantly higher $(\mathrm{p}<0.01)$ than in young people. In both gruops COP dislocation in transverse axis and the mean velocity of COP sways significantly rose when eyes were closed, but COP dislocation did not vary in sagital axis. Older persons ' COP dislocation in transverse axis was significantly higher in higher frequencies $(0.312 \div 1.25)$. This difference was more pronounced with eyes closed. Meanwhile, older people with eyes opened in sagital. axis showed significantly higher slow $(0.078 \div 0.156 \mathrm{~Hz}) \mathrm{COP}$ dislocation. The COP dislocation was significantly higher over the whole frequency range with eyes closed.

Conclusions: a) $30-45$ years-old people's postural control is less effective compared to young people (20-24 years). b) Both in young and as in older people COP dislocation in transversal axis and the average fluctuation rate significantly rise with eyes closed, but fluctation amplitude in sagital axis does not vary. This indicates that vision is more important for COP dislocation in transversal axis, but not in sagital axis.
\end{abstract}

Keywords: stabilography, postural control, wavelet transform.

Gauta $2010 \mathrm{~m}$. vasario $1 \mathrm{~d}$.

Received on February 1, 2010

Priimta $2010 \mathrm{~m}$. balandžio $1 \mathrm{~d}$.

Accepted on April 1, 2010
Kazimieras Muckus

Lietuvos kūno kultūros akademija

(Lithuanian Academy of Physical Education)

Sporto g. 6, LT-44221 Kaunas

Lietuva (Lithuania)

Tel +370 37302635

E-mailk.muckus@1kka.lt 